\title{
Design and Evaluation of an Educational Platform for Implementing and Testing Bilateral Control Algorithms
}

\author{
José M. Cogollor, Ignacio Galiana \\ Centro de Automática y Robótica - CAR (UPM - CSIC) \\ Universidad Politécnica de Madrid \\ Madrid, Spain \\ jm.cogollor@upm.es; ignacio.galiana@upm.es
}

\author{
Jorge Barrio, Manuel Ferre, Rafael Aracil \\ Centro de Automática y Robótica - CAR (UPM - CSIC) \\ Universidad Politécnica de Madrid \\ Madrid, Spain \\ jordi.barrio@upm.es; m.ferre@upm.es; \\ rafael.aracil@upm.es
}

\begin{abstract}
This paper describes the design and evaluation of a new platform created in order to improve the learning experience of bilateral control algorithms in teleoperation. This experimental platform, developed at Universidad Politécnica de Madrid, is used by the students of the Master on Automation and Robotics in the practices of the subject called "Telerobotics and Teleoperation". The main objective is to easily implement different control architectures in the developed platform and evaluate them under different conditions to better understand the main advantages and drawbacks of each control scheme. So, the student's tasks are focused on adjusting the control parameters of the predefined controllers and designing new ones to analyze the changes in the behavior of the whole system. A description of the subject, main topics and the platform constructed are detailed in the paper. Furthermore, the methodology followed in the practices and the bilateral control algorithms are presented. Finally, the results obtained in the experiments with students are also shown.
\end{abstract}

Keywords-innovative education; bilateral control; teleoperation; laboratory experimentation

\section{INTRODUCTION}

All the experiments carried out in the laboratory are an essential part of engineering education. They let professors complement theoretical lectures as well as illustrate and validate analytical concepts which introduce students to professional practices, social development and teamwork skills in a technical environment [1]. These reasons show the student's so high expectations for attending practices in the laboratory.

During the last decades, many innovative trends are being spreading in the teaching - learning process of natural sciences, primarily, those related to laboratory practices which are the basis for the learning and improvement of skills in research developments.

It has been said many times that the laboratory includes the workplace, in education and research, where different experiments and discoveries are conducted about some biological or physic - chemical phenomenon or change.
Moreover, that experimental work lets students develop their power of observation, analysis, discrimination, classification, synthesis, structure of reports and each experience will generate curiosity, perseverance and creativity. All these aspects lead to the development of skills and attitudes for research that optimize learning together and promote students learn how to research investigating.

To carry out this main purpose such as research from the laboratory there must be adequate conditions in infrastructure, materials and labor, as well as training laboratory technicians and, above all, a new attitude that will enable teachers to locate the laboratory as a primary tool for teaching and research. This new attitude also involves finding new ways of work, always considering the rules set out in the laboratory.

In this case, the paper is focused on the use of laboratory for Bilateral Control purposes. The bilateral control algorithms are an essential part in teleoperation field and lets the human operator obtain the maximum amount of information from the remote environment where a robot is executing complex tasks or manipulating different kind of objects [2], [3], [4], [5]. The operator must feel as if he/she is doing the task directly in the remote environment.

In order to introduce students to teleoperation skills, the majority of the practices developed in this field are involved in virtual worlds and Distance Laboratory Systems (DLS) where students do many exercises with simulation tools analyzing graphical and numerical data [6], [7], [8].

For example, references [9], [10] show how students can simulate and teleoperate virtual robots using e - learning environments.

Considering the main goal of bilateral control algorithms, what this paper proposes is an uncomplicated and ergonomic platform which has been developed to ensure the correct learning in bilateral control, an important part of the subject "Telerobotics and Teleoperation" which belongs to the Master Program on Automation and Robotics, offered by Universidad Politécnica de Madrid. This new educational platform and methodology implies a great change in the way of teaching this field because students can experiment physically the real 
effects of teleoperation systems and feel the corresponding force sensations depending on the algorithm implemented in a real system instead of using virtual robots.

So, the paper is divided into several sections: section II explains the organization of the subject mentioned above.

After that, a very brief introduction to teleoperation and bilateral control is done in section III. The platform constructed is presented in section IV. Once the hardware is understood, the methodology used in the practices and the main algorithms proved are detailed in section V. For its part, Section VI is focused on the results from the laboratory experiments and students survey and finally, a summary of the main idea from the paper is given in section VII.

\section{SubJeCt ANALysis OF TELEROBOtics AND TELEOPERATION}

The contents of the subject "Telerobotics and Teleoperation" are adjusted to cover up the most important aspects of the field assuming a realistic balance between workload and personal dedication of the students.

The main goal of this subject is the design and development of teleoperated systems which involve, especially, the design of regulators of bilateral control systems. For this purpose, the main areas students must improve their knowledge in are the following ones:

- Introduction to telerobotics.

- Control architectures in teleoperation.

- Interfaces and operator senses in teleoperation.

- Haptic devices.

- Bilateral control based on classical techniques.

- Passivity based techniques for bilateral systems stability.

- Transparency and perception of the remote environment in presence of time delays in communications.

- Bilateral control based on States Convergence algorithm.

- Internet protocols in telerobotics.

- Main industrial applications for teleoperation.

In order to achieve all the objectives presented above, the subject is made up by 75 hours (3 ECTS). The following figure shows this distribution:

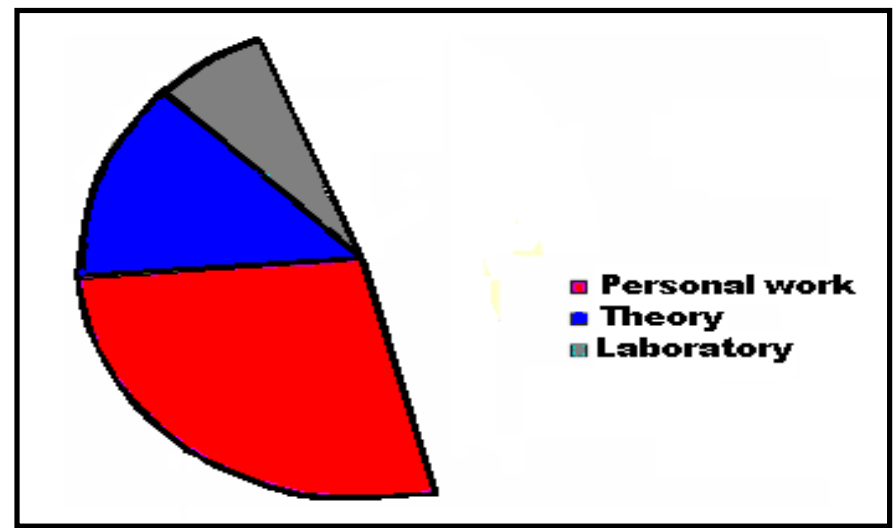

Figure 1. Distribution of hours in the subject
- 10 hours focused on practices in the laboratory.

- 20 hours for theoretical purposes.

- 45 hours of personal work.

On the one hand, practices in the laboratory are focused on the interaction with a physical system whose architecture is shown later. The goal is to implement and prove different bilateral control schemes and let students adjust the parameters of the regulators to achieve the required behavior. Finally, students have to complete a report at home with some exercises based on what they have learned from the laboratory experiments.

On the other hand, the theoretical purposes are fulfilled by lectures focused on teaching the theoretical contents of each topic. Classes are organized in two - hour sessions whose topics are mainly taught using slides. These slides are prepared by the professors and provided to students, although complementary bibliography is also recommended. A common classroom is used for these activities.

Finally, the personal work involves problem solving of the exercises proposed once students have done the practices in laboratory. Furthermore, they are given a self - assessment test to check if they have acquired the necessary knowledge after laboratory attendance.

\section{INTRODUCTION TO BILATERAL CONTROL IN TELEOPERATION}

According with the main topics to be learned in the practices, it is important to give a short introduction to bilateral control in teleoperation before the platform constructed is presented.

The origins of teleoperation were motivated by the requirements of the nuclear industry. In 1948 Ray Goertz, from the Argonne National Laboratory, United States, developed the first system of teleoperation based on master - slave architecture, in which both manipulators were connected mechanically [4]. Since then, electric servo - controlled teleoperated systems began to emerge.

In teleoperation of robots, the human operator is located in a local workstation executing a task by manipulating a device known as "master". That task is performed in a remote environment through a manipulator robot known as "slave". The movements and path of the slave must be the same as the master performs. This is achieved thanks to a communication channel between both devices.

In teleoperated tasks focused on manipulation of objects, the human operator primarily uses two of his/her senses: vision and perception of forces. The signals of the interaction forces between the remote environment and the slave robot, and the position of both devices can be fed back through the same communications channel.

The values of the interaction strength can be displayed on a computer monitor (visual feedback of force) or can be entered directly into the actuator of the master device to allow the operator "feel" the force (force reflection). A teleoperation system characterized in this way, in which the human operator sends commands through a local system to a system handling remote operations and simultaneously receives the interaction forces in his/her hand, is called teleoperated bilateral control system, because the information flows bidirectionally [5]. 
There are several techniques to be implemented in order to achieve bilateral control, and the most important ones will be shown in section $\mathrm{V}$.

\section{DESCRIPTION OF THE EdUCATIONAL PLATFORM}

As shown in Figure 2, the educational platform built is composed by two identical devices, one acting as master and the other as slave:

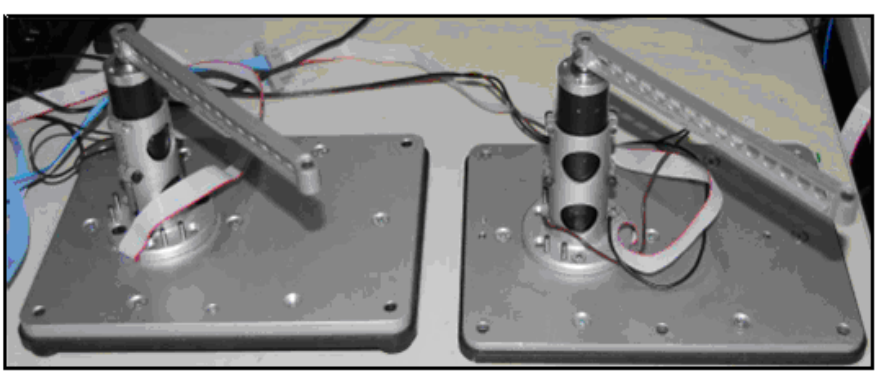

Figure 2. Educational platform for bilateral control study

Both master and slave manipulators are a DC electric motor with brushes from MAXON. Each motor has a MR encoder associated in order to obtain angular position measurements and a force sensor from ATI. It is important to mention that both devices present the same reduction factor (114).

Among the products available to control and design the communication with the platform, CompactRIO hardware from National Instruments has been chosen due to the need of robustness.

The device CompactRIO is an advanced data acquisition and control system for applications that require high performance and robustness. This device incorporates a realtime processor and a re - configurable FPGA for embedded or distributed applications.

To program the controller and FPGA, LabVIEW programming environment is used. It is a graphical tool for testing, design and control. The language used is called language $G$.

Programs developed with LabVIEW are called virtual instruments or VI's and its origin comes from the instrument control. Its main feature is the ease of use, applied for both professional programmers and people with little programming knowledge.

The control of the motors is focused on the following tasks:

- Current control.

- State monitoring.

- Sensor acquisition.

- PWM modulation.

- $\quad$ Signal sampling.

Bearing in mind that the platform is used by students there are many requirements to be fulfilled which are presented below:

- Open - and - modular architecture platform in order to let students reconfigure the platform to prove different kinds of tasks.
- High computing capacity to implement several control algorithms.

- Easy use of the material available in the laboratory.

- Robust and compact design.

- Ergonomic, light - weight and not very complex.

- Reliability in data and communication.

The transfer function which represents the model of both motors is the following one:

$$
\frac{\theta(s)}{I(s)}=\frac{4,9932}{0,0131 \cdot s^{2}+3,119 \cdot s}
$$

This transfer function corresponds to the relationship between the motor angular position $\theta(\mathrm{t})$ and the current that flows through it $\mathrm{I}(\mathrm{t})$. The reason for choosing that relationship considering the current as an input is the necessity of taking into account the corresponding saturation of both motors provided by the technical specifications $(0.7 \mathrm{~A})$. The transfer function lets students analyze the stability of the whole control system before doing the corresponding practices.

\section{Methodology used in Practices and Bilateral CONTROL ALGORITHMS}

The students will be able to test and experience the effects of major bilateral control algorithms studied in class, and their main advantages and disadvantages.

The essential part of the development work will be carried out using the real experimental platform where the implementation of the algorithms is achieved using LabVIEW programming as mentioned in the previous section.

In turn, a brief introduction to man - machine interaction using simple interfaces also developed in LabVIEW is also proposed for the pupils.

The most important bilateral control algorithms to be implemented are:

- Position - Position Control.

- Force-Position Control (with time delays).

- Four-Channel architectures.

- States Convergence based Control.

It is important to mention that in order to improve the stability of the system in presence of time delays, the passivity based algorithm known as Scattering will be also implemented in the second type of control.

For more detailed information about this kind of algorithms and their functioning, please refer to [11].

\section{A. Position-Position Bilateral Control}

The following figure shows the block diagram of this type of control: 


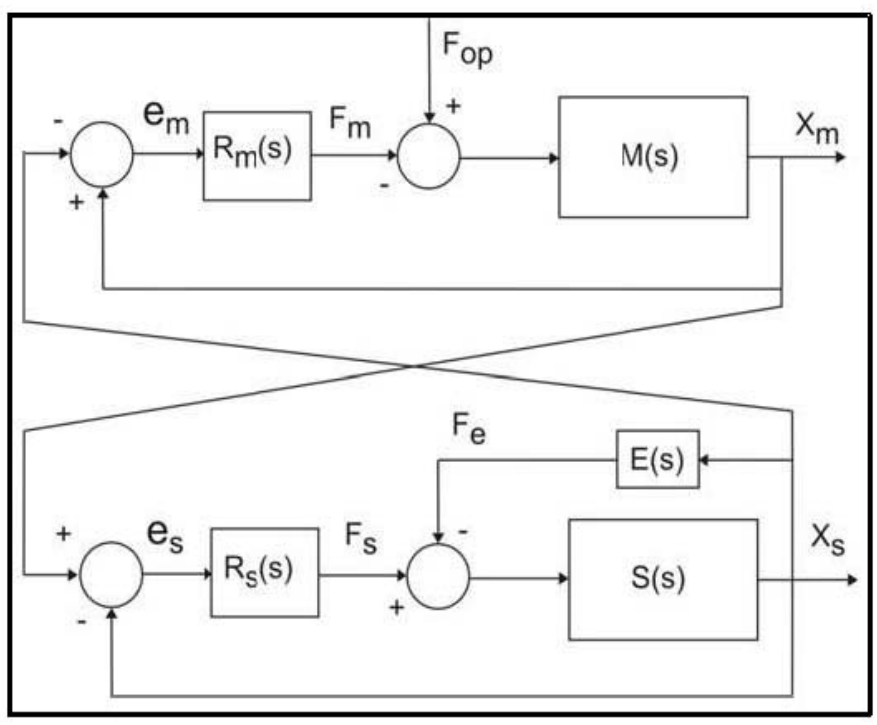

Figure 3. Block diagram of Position - Position control

The personal work proposed in the laboratory is focused on checking the stability of the platform and the transparency (forces perception by students) depending on changes in the control parameters of the regulators $\mathrm{Rm}(\mathrm{s})$ and $\mathrm{Rs}(\mathrm{s})$.

After that, students must do at home a theoretical analysis of the stability and the perception by the operator in this type of algorithm in terms of variations (extreme cases) of the contact with the environment $\mathrm{E}(\mathrm{s})$, justifying numerically what they have experimented in the real tests.

\section{B. Force-Position Bilateral Control with Time Delays}

The following figure shows the block diagram of this type of control:

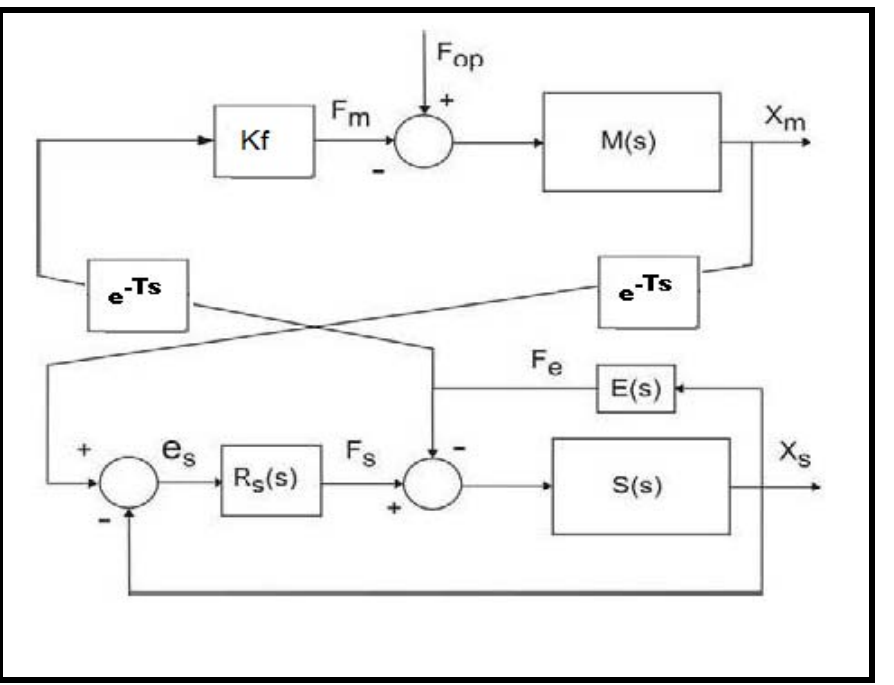

Figure 4. Block diagram of Force - Position control with time delays

In this case, the personal work proposed in the laboratory is focused on checking the instability of the platform and the transparency (forces perception by students) depending on changes in the control parameters of the regulator $\mathrm{Rs}(\mathrm{s})$ and the called reflection constant $\mathrm{K}_{\mathrm{f}}$, in presence of a time delay which value is also modified by the students.

As it is proved in previous works, teleoperated systems suffer negative effects when time delays in the communication channel occur and it can be solved by implementing the Scattering algorithm (Figure 5). This new implementation let the system improve and increase its stability, something essential, especially, in aerospace teleoperated applications.

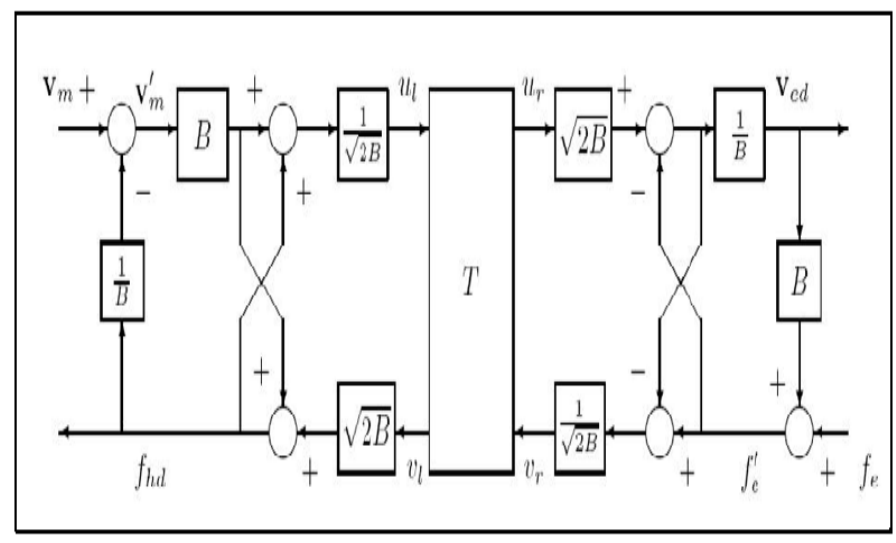

Figure 5. Block diagram of Scattering algorithm

So, students can implement this additional algorithm in order to prove the better behavior of the whole system.

Finally, they must create at home a control diagram in Matlab/Simulink to simulate the scattering algorithm and verify that the system turns out to be more stable although time delays exist as demonstrated in the real experiments. This verification will be done by showing graphs associated with the positions of both devices.

\section{Four-Channel Architectures}

The following figure shows the block diagram of this type of control:

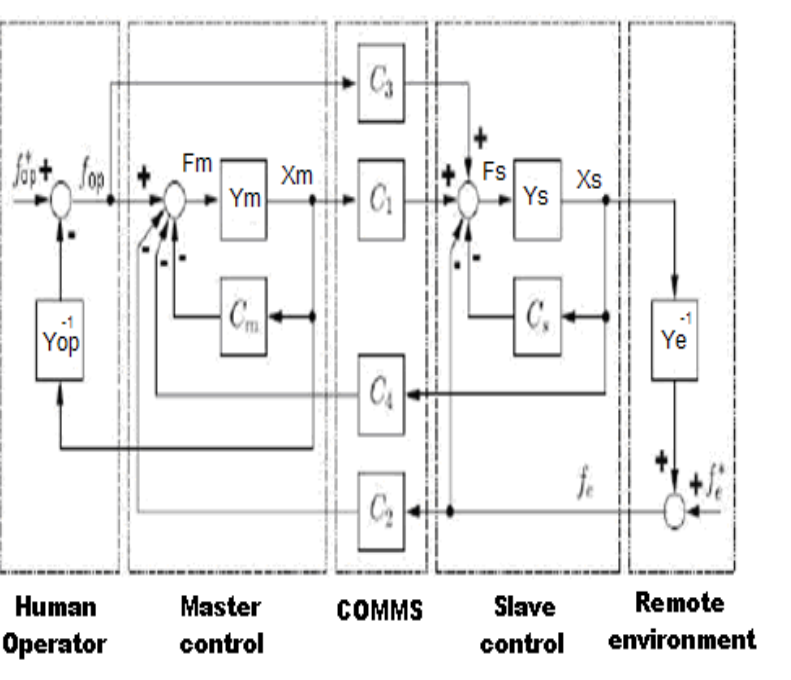

Figure 6. Block diagram of Four - Channel architecture 
As usual, the personal work proposed in the laboratory is focused on checking the stability of the platform and the transparency. This is function of the control parameters $\mathrm{C}_{1}, \mathrm{C}_{2}$, $\mathrm{C}_{3}, \mathrm{C}_{4}, \mathrm{Cm}$ and $\mathrm{Cs}$.

Finally, the students must show theoretically that this new architecture is a general approach of the previous and more basic algorithms. So, choosing an adequate value of the control parameters, they can obtain the others architectures.

\section{States Convergence Based Control}

The last algorithm to be implemented is shown in the following figure:

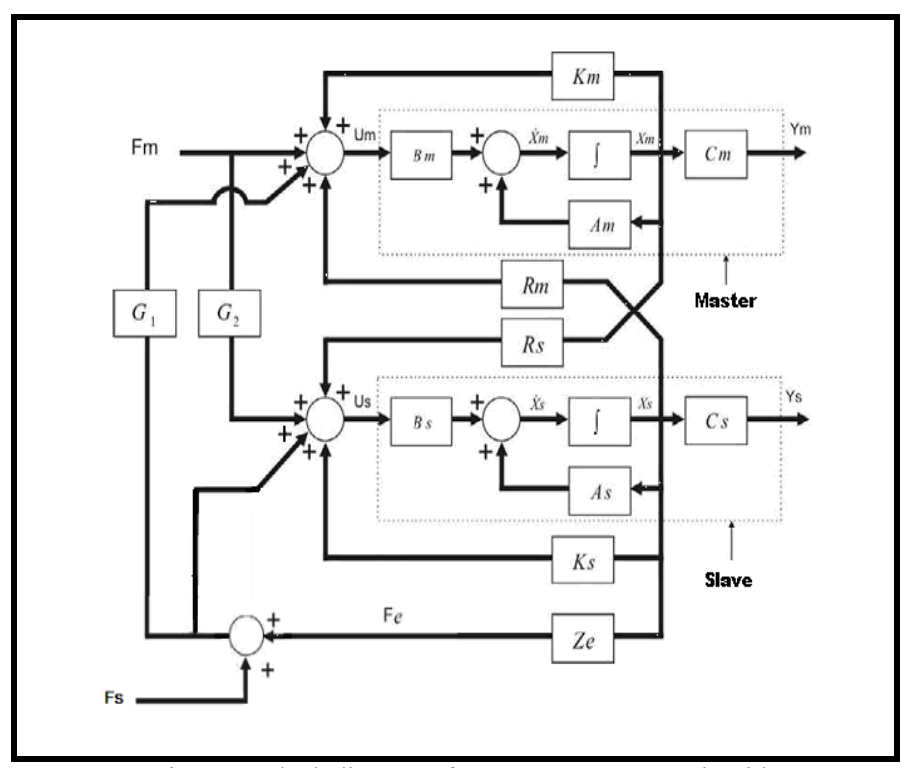

Figure 7. Block diagram of States Convergence algorithm

As in the previous test, the personal work proposed in the laboratory is focused on checking the stability of the platform and the transparency. This is function of the control parameters $R_{m}, R_{s}, K_{m}, K_{s}, G_{1}$ and $G_{2}$.

As final work, the students must show theoretically that this new architecture is also a general approach of the previous algorithms. So, choosing an adequate value of the control parameters, they can obtain the others architectures.

Finally, the students use an interface in order to change the corresponding control parameters in each scheme. Figure 8 represents one of the interfaces designed also in LabVIEW.

While manipulating the master device in order to proof that the slave one follows the same path and the contact forces are reflected in the master to the students, they can check this behavior and obtain relevant data from the whole system thanks to each interface (one per control scheme).

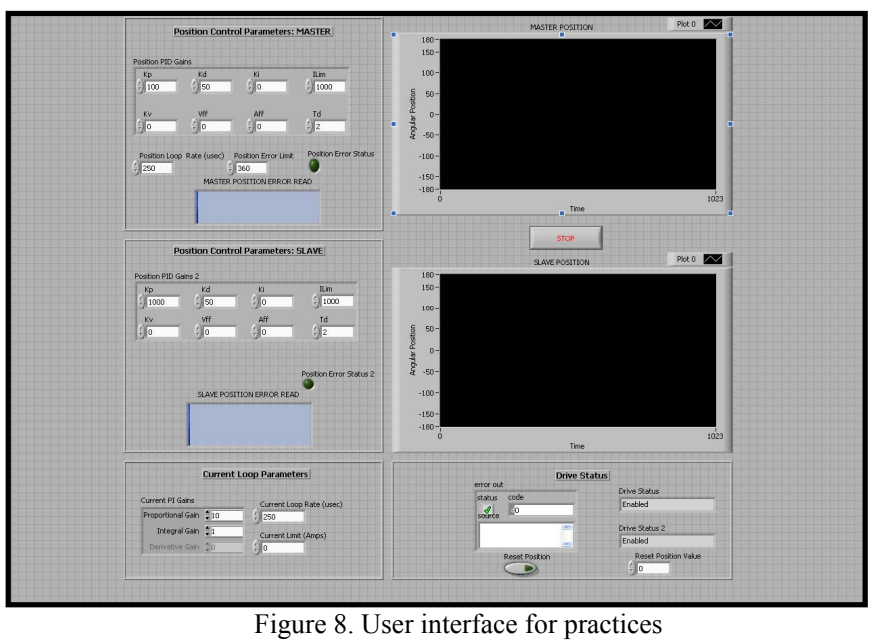

The main information the students deal with in the interfaces is:

- Angular position of each device (graphs).

- Angular velocity of each device (numerical data and graphs).

- Control parameters of the regulators (variable controls).

- Forces in each device (numerical data and graphs).

- Position errors (numerical data and graphs).

- Position error limits (variable controls).

- Force errors (numerical data and graphs).

- Information of the whole system status (alarms, failures).

- $\quad$ Sampling frequencies (variable controls).

- Current limit (variable control).

- Current control parameters (variable controls).

\section{Results Obtained In THE PRACTICES}

The results obtained in this so interesting way of learning were quite good. The students were very motivated with the use of this platform because they are not used to working with real systems and proof by themselves all that learned in lectures.

A survey about this activity was carried out. It took into account the following aspects:

- Laboratory instructor.

- Student personal dedication.

- General work assessment.

According with the last aspect presented in the survey, the assessment of the whole practical work in the laboratory, the following issues was pointed out:

- Improvement in the knowledge of the importance of bilateral control in teleoperation.

- Quality level of the experimentation of the techniques learned in class.

- Importance and necessity of the work for personal academic training and for the understanding of the general subject. 
- Balance between the total hours which compose the subject and those needed to do the practical works.

- Level of suitability and utility of the platform to ensure the correct learning of the algorithms.

- Recommendation of the activity for future students in the master.

- Most important difficulties while doing the work and possible solutions.

- Main advantages and disadvantages.

- $\quad$ Suggestions and ideas.

The survey was scaled from 1 to 5 points and practically all the students considered that this activity proposed is interesting for them and for the correct learning. They were satisfied with the platform and they enjoyed themselves while doing the practices. It is important to mention that they showed at any time interest in doing it.

However, they complained about the workload considering those activities to be done in the final report of the practices. In any case, they recommend the use of this platform for future courses and they improved their knowledge in the field as professors checked in the final exam results.

Finally, it is important to comment that the use of this platform puts the figure of the laboratory instructor into a new role. The instructor's role in this educational experience is no longer that of a presenter of information but rather than of a guide or coacher, who helps the student in the learning process. This function is the inevitable result of the evolution of the role of the instructors in education. With the use of this kind of practices instructors evolve into their new role naturally. In that sense, this experience is also very interesting and useful for instructors and teachers, and constitutes a learning experience for them.

\section{CONCLUSIONS}

The platform constructed composed by simple components and easy to be reconfigured in the laboratory, especially, its flexibility and robustness, makes it a useful resource for learning.

Although the instructor must help the students be aware of the whole hardware architecture and the user interface, it is expected that the platform will be increasingly used in this field of engineering during the following courses and guided visits.

One of the values of these good experiments conducted in a real platform instead of using simulations tools is their ability to implement and proof concepts previously learned. This properly designed educational platform enables students to internalize major concepts. Furthermore, the educational platform can provide effective learning, allowing students to practice skills in a real environment.

It is clear that the success of an educational platform requires an emphasis on the educational components rather than just the algorithms to be implemented. The goals of the platform must be not only to provide a practice environment, but also to provide a specific learning environment.
A powerful educational experience focuses on the learning objectives and frames other elements around it. It cannot be decided what to implement or what to reward until the learning objectives and the pedagogical elements have been established.

\section{ACKNOWLEDGMENT}

This work is partially funded by the Vice - Rectorate of Ordenación Académica y Planificación Estratégica of the Universidad Politécnica de Madrid. Furthermore, this work was partially supported by Comunidad de Madrid through the network TECHNOFUSION, under the TEMAR project under grant DPI2009-12283 from the Ministerio de España de Innovación y Ciencia (MICINN) and the EFDA GOT-RH project.

\section{REFERENCES}

[1] E. Lindsay, P. Long and PK Imbrie, "Remote Laboratories Approaches for the Future," $37^{\text {th }}$ ASEE/IEEE Frontiers in Education Conference, October $10^{\text {th }}-13^{\text {th }}, 2007$, Milwaukee.

[2] Manuel Ferre, Jordi Barrio, Claudio Melchiorri, Juan M. Bogado, Pedro L. Castedo and Juan M. Ibarra. "Experimental Results on Bilateral Control Using an Industrial Telemanipulator". In M. Ferre et al. (Eds): Advances in Telerobotics, STAR 31, pp. 177190. SpringerVerlag. 2007.

[3] Manuel Ferre, Martin Buss, Rafael Aracil, Claudio Melchiorri and Carlos Balaguer (Eds.). "Advances in Telerobotics". STAR 31, SpringerVerlag. 2007.

[4] Raymond Goertz. "Manipulators Systems Development at ANL". Proceedings of the $12^{\text {th }}$ Conference on Remote Systems Technology, ANS. 1964.

[5] Postigo, J., Lage, A. Carelli, R. "Sistema de Teleoperación de Robots con Realimentación Cinestésica y Visual de Fuerza". Annuals from VIII Congreso Latinoamericano de Control Automático. Vol. I, pp. 85-90. Viña del Mar, Chile. November $9^{\text {th }}-13^{\text {th }}, 1998$.

[6] Iván Santana Ching, Luis Hernández Santana, Manuel Ferre Pérez, Rafael Aracil Santonja, Enrique Pinto and Ángel García Beltrán. "Distance Practices in Subjects of Automatic Control". IEEE EDUCON Education Engineering 2010. April $14^{\text {th }}-16^{\text {th }}$, Madrid, Spain.

[7] L. Hernández, H. Sahli, I. Santana, A. Sartorius, E. Rubio and R. Ballesteros. "Plataforma para la realización de actividades prácticas a distancia en tiempo real. Potencialidades de utilización en la educación superior". UNIVERSIDAD 2006, Conference "La Virtualización de la Educación Superior", February 2006, La Habana, Cuba.

[8] A. Sartorius, L. Hernández, R. Aracil, Á. Rubio and I. Santana, "Platform for distance development of complex automatic control strategies using Matlab," The International Journal of Engineering Education, special issue on Matlab and Simulink in Engineering Education, Vol. 21, No. 5, pp. 790 - 797, 2005.

[9] Aldo R. Sartorius Castellanos, Luis Hernández Santana, Rafael Aracil Santonja, Ángel Ernesto Rubio, Iván Santana Ching. "Virtual and remote laboratory for robot manipulator control study". The International Journal of Engineering Education, special issue on Robotic Education. Vol. 22, No. 4, pp. 702 - 710, 2006.

[10] Carlos A. Jara, Francisco A. Candelas, Fernando Torres. "Virtual and Remote Laboratory for Robotics E - Learning". $18^{\text {th }}$ European Symposium on Computer Aided Process Engineering - ESCAPE 18 Bertrand Braunschweig and Xavier Joulia (Editors) (C) 2008 Elsevier B.V./Ltd. All rights reserved.

[11] Juan Manuel Bogado Torres. "Control Bilateral de robots teleoperados por convergencia de estados". PhD Thesis. Universidad Politécnica de Madrid. Madrid 2007. 